\title{
Morfología Dental de una Serie Prehistórica de Araucanos Provenientes de la Patagonia Argentina y su Relación Biológica con Otras Poblaciones Prehistóricas Argentinas y del Mundo
}

\author{
Dental Morphology in a Prehistoric Sample of Araucanos From Patagonia and \\ His Biological Relationship With Other Prehistoric Populations From Argentina and \\ the World
}

"Gabriel A. Bollini; **Carlos D. Rodríguez-Flórez; **Sonia E. Colantonio \& *** Marta G. Méndez

BOLlini, G. A.; RODRÍGUEZ-FLóREZ, C. D.; COLANTONIO, S. E. \& MÉNDEZ, M. G. Morfología dental de una serie prehistórica de araucanos provenientes de la Patagonia argentina y su relación biológica con otras poblaciones prehistóricas argentinas y del mundo. Int. J. Morphol., 24(4):705-712, 2006.

RESUMEN: Se estudió la prevalencia de 25 rasgos dentales en un grupo de cráneos adultos prehispánicos, conservados en el Museo de La Plata (Argentina). Fueron analizadas ambas arcadas y la totalidad de las piezas dentales de la dentición permanente excepto los terceros molares. El principal objetivo de este estudio es establecer el patrón morfológico dental, según las frecuencias absolutas y relativas de los rasgos que caracterizan a la dentición de la serie Araucanos. Se puede concluir, por las frecuencias presentadas en los rasgos analizados, que la muestra presenta similitudes con las poblaciones mongoloides sinodontes y se aleja de las poblaciones europeas y africanas.

PALABRAS CLAVE: Morfología dental; Rasgos dentales; Araucanos prehistóricos; Medida media de la divergencia (MMD); Componente mongoloide.

\section{INTRODUCCIÓN}

Desde el punto de vista evolutivo, el valor antropológico de la dentición humana subyace en la consideración teórica que asume la presencia de los caracteres dentarios como una condición morfológica de fuerte control genético (Hrdlicka, 1921, Townsend \& Martin, 1992), permitiendo el establecimiento de relaciones directas entre igualdad estructural y filiación poblacional.

Es muy probable que los grupos que posean una morfología dentaria similar estén relacionados biológicamente entre sí. De esta manera, el estudio de la forma en la dentición humana ha permitido develar patrones de filiación biológica entre poblaciones antiguas e inferir procesos microevolutivos asociados a pautas de poblamiento en amplias zonas geográficas de Asia (Hanihara, 1966), Oceanía (Hanihara, 1990), y América principalmente (Dahlberg, 1963, Devoto et al., 1968, Turner, 1984 y 1989, Scott \& Turner 1997).
Los estudios de morfología dental con enfoque antropológico defienden la morfología comparativa como la base metodológica principal en el análisis poblacional. Este tipo de estudios establece relaciones biológicas entre los individuos de un mismo grupo y con individuos de otras poblaciones y zonas geográficas. En este trabajo se caracterizan las frecuencias de las variables dentales más significativas, para lograr un perfil morfológico de la muestra estudiada, que permita futuras comparaciones entre poblaciones humanas prehistóricas de Sur América.

\section{MATERIAL Y MÉTODO}

Se realizó el análisis dental en 36 cráneos de araucanos prehistóricos, de probables adultos maduros (Figs. 1 y 2), procedentes de la Provincia de la Pampa, Argentina,

\footnotetext{
* Museo de Historia Natural y Facultad de Ciencias Naturales - Universidad Nacional de La Plata, Argentina.

* Cátedra de Antropología Biológica y Cultural, Facultad de Ciencias Naturales - Universidad Nacional de Córdoba, Argentina

${ }^{* * *}$ Investigador del CONICET, Argentina.
} 
grupo aborigen que toma su nombre por la región chilena de origen y que a sí mismos se llamaban Mapuches, con amplísima difusión en Argentina, donde llegaron a ocupar, en tiempos de la colonia, todo el territorio pampeano y el norte de La Patagonia. La dentición estudiada pertenece a cráneos de la División de Antropología del Museo de La Plata, Argentina, los cuales se encuentran ordenados según secuencias de pertenencia definidas por el catálogo de dicha División.

La información cronológica asociada a las muestras estudiadas no pudo ser recolectada con precisión, debido a que la mayor parte de los cráneos fueron exhumados sin metodología de control estratigráfico, entre finales del siglo XIX y la década de los años 50 del siglo XX. Por ello,

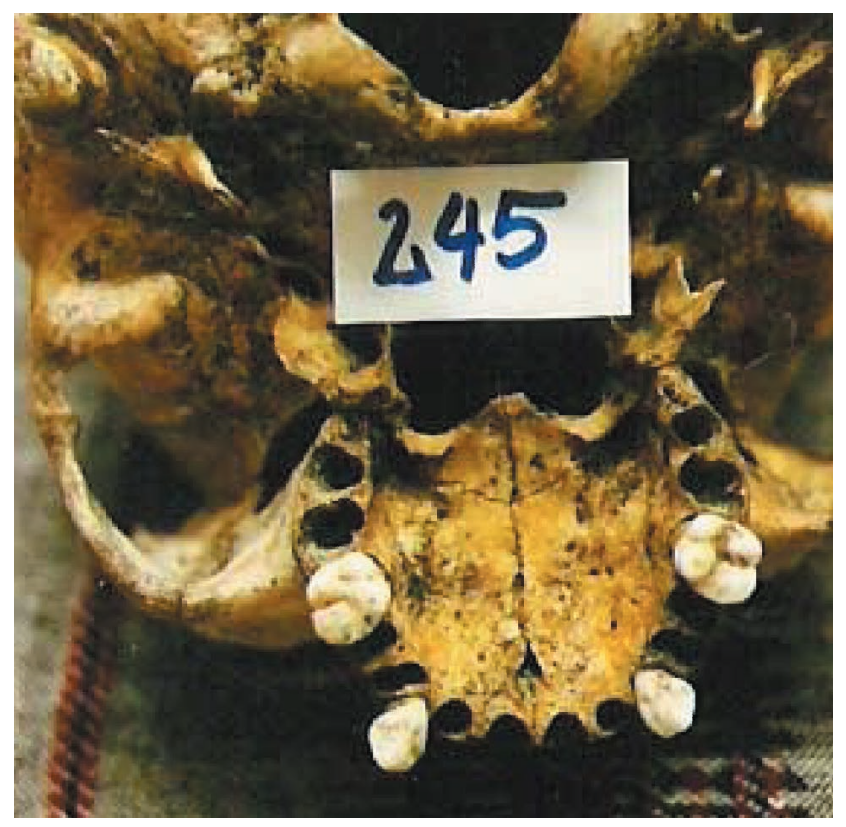

Fig. 1. Cráneo de la serie araucana proveniente de la Patagonia Argentina.

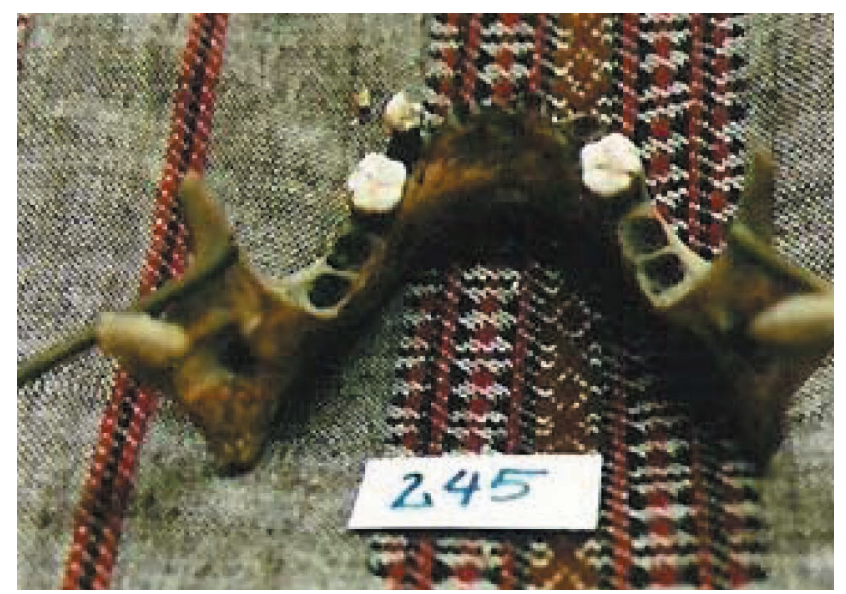

Fig. 1. Mandíbula de la serie araucana proveniente de la Patagonia Argentina. en la planificación de desarrollo del trabajo se decidió resolver el problema utilizando un criterio feneticista ampliamente utilizado para estudios intraespecíficos. No podemos considerarlos los cráneosestrictamente contemporáneos debido a la falta de fechados en la gran mayoría de ellos. No obstante, ninguno de los cráneos analizados pertenece a las primeras etapas del poblamiento, que pudiera llevar a considerarlos como "paleo - americanos". Siguiendo este razonamiento, la organización cronológica se clasificó dentro del grupo llamado protohistórico, cuya antigüedad no sobrepasa los 1500 años y observa su permanencia hasta tiempos de la Conquista y posteriores (Marcellino \& Colantonio, 2000).

Se analizaron 288 incisivos centrales y laterales, de la porción maxilar y mandibular, 144 caninos superiores e inferiores, 288 premolares tanto anteriores como posteriores en ambas arcadas dentarias, 144 primeros molares y 144 segundos molares superiores e inferiores. Sin embargo, gran parte de estas piezas presentaban estructura incompleta o ausencia de la misma, reduciendo la lectura de los rasgos escogidos a los siguientes:

De los 504 dientes por hemimandíbula (considerados tanto izquierdos como derechos), sólo se han observado los rasgos en 8 incisivos centrales superiores y 8 incisivos laterales superiores, 17 caninos superiores, 15 primeros premolares y 13 segundos premolares, 13 primeros molares y 11 segundos molares. Para la arcada inferior, se analizaron 5 incisivos anteriores, 6 incisivos laterales, 7 caninos, 11 primeros premolares, 10 segundos premolares, 11 primeros molares y 10 segundos molares, lo que suma un total de 145 piezas, correspondiente al $28.77 \%$ de la muestra, porcentaje de piezas factible de análisis, debido esto a los altos niveles de atrición dentaria y a la pérdida de dientes postmortem.

Respecto a la lectura de los rasgos sólo se han obtenido de aquellos dientes en que su corona presenta clara identificación de los mismos. En la Tabla I se detallan los rasgos, el grado de expresión y las referencias utilizadas para la evaluación de las variables analizadas y en la Tabla II las procedencias de colección y geográfica y el número de cráneos utiliados en el estudio.

Análisis estadístico. Una vez extraídas las frecuencias absolutas y relativas se procedió a la comparación de la muestra con diferentes grupos de Argentina y el mundo. Para el primer caso se han tomado los datos un conjunto de cráneos del Noroeste argentino (Bollini et al., 2004. Tabla II), mientras que para la comparación con otras poblaciones mundiales se han extraído de los valores publicados por Irish (1997). 
Se aplicó la Medida Media de Divergencia (MMD) para calcular las distancias biológicas entre la serie araucana analizada y las diversas poblaciones consideradas. El tratamiento de los datos, para el cálculo de la Medida Media de Divergencia, se basó en un trabajo sobre transformación angular de frecuencias del coeficiente $\mathrm{q}$ (tetha), la cual se define como el arcoseno (1-2p), y donde $\mathrm{p}$ es la frecuencia. La varianza de $\mathrm{q}$ es simplemente $1 / \mathrm{n}$. (Richards \& Telfer, 1979).
La fórmula final utilizada para el cálculo de la distancia fue, según la MMD:

$$
\left(\mathrm{q} 1-\mathrm{q}^{2}\right) \sum-\left(1 / \mathrm{n} 1+1 / \mathrm{n}^{2}\right)
$$

Calculadas las distancias parciales se halla la MMD total por sumatoria de las mismas, teniéndose en cuenta la corrección de Hanihara (1976). Cuando el valor de la distancia es negativo, la distancia es considerada cero.

Tabla I. Variables analizadas, grados de expresión y referencias bibliográficas utilizadas en el trabajo Morfología dental de una serie prehistórica de araucanos provenientes de la Patagonia Argentina y su relación biológica con otras poblaciones prehistóricas argentinas y del mundo.

\begin{tabular}{|c|c|c|}
\hline Rasgo & Grados de expresión & Referencias bibliográficas \\
\hline Estructura en pala & $4 \mathrm{~g}$ rados de expresión: ausencia, pala & Hrdlicka, 1920 (con modificaciones). \\
\hline Doble pala & $\begin{array}{l}4 \text { grados de ex presión: ausencia, tipo } 1 \text {, } \\
\text { tipo } 2 \text {, tipo } 3 \text { y tipo } 4 \text {. }\end{array}$ & $\begin{array}{l}\text { Dahlberg \& Mikkelsen, } 1947 . \\
\text { Snyder, } 1960 . \\
\text { Devoto, } 1973 .\end{array}$ \\
\hline Tubérculo lingual & $\begin{array}{l}4 \text { grados de expresión: ausencia, leve, } \\
\text { moderada y marcada. }\end{array}$ & Goaz \& Miller; 1966 (con modificaciones). \\
\hline Surco del tubérculo lingual & $\begin{array}{l}2 \mathrm{~g} \text { rados de expresión: presencia y } \\
\text { ausencia. }\end{array}$ & Goaz \& Miller, 1966. \\
\hline $\begin{array}{l}\text { Hendidura de los rebordes } \\
\text { marginales linguales }\end{array}$ & $\begin{array}{l}2 \mathrm{~g} \text { rados de expresión: presencia y } \\
\text { ausencia. }\end{array}$ & Devoto, 1973. \\
\hline $\begin{array}{l}\text { Número de cú spides } \\
\text { premolares }\end{array}$ & $\begin{array}{l}2 \text { grados de expresión: premolares } \\
\text { monocuspídeos o bicuspídeos. }\end{array}$ & Rodríguez-Cuencua, 1999. \\
\hline Hipocono & $\begin{array}{l}4 \text { grados expresión: ausencia, hipocono } \\
\text { menor al metacono, } \\
\text { hipocono igual al metacono e hipocono } \\
\text { mayor al metacono. }\end{array}$ & $\begin{array}{l}\text { Dahlberg, } 1951 . \\
\text { Brabant, } 1972 . \\
\text { Turner } \text { et al., } 1991 .\end{array}$ \\
\hline Tubérculo de Carabelli & $\begin{array}{l}4 \text { grados de expresión: ausencia, fosa, } \\
\text { canal, cúspide adherida, cúspide libre. }\end{array}$ & $\begin{array}{l}\text { Kraus, } 1951 \text { (con modificaciones). } \\
\text { Brabant, } 1972 .\end{array}$ \\
\hline Paracónulo & $\begin{array}{l}2 \mathrm{~g} \text { rados de expresión: presencia y } \\
\text { ausencia. }\end{array}$ & Rodríguez-Cuenca, 1999. \\
\hline Metacónulo & $\begin{array}{l}2 \mathrm{~g} \text { rados de expresión: presencia y } \\
\text { ausencia. }\end{array}$ & $\begin{array}{l}\text { Korenhof, } 1960 . \\
\text { Harris \& Bailit, } 1980 .\end{array}$ \\
\hline Sexta cúspide & $\begin{array}{l}2 \mathrm{~g} \text { rados de expresión: presencia y } \\
\text { ausencia. }\end{array}$ & $\begin{array}{l}\text { Hanihara, } 1966 \text { (con modificaciones). } \\
\text { Dahl berg, } 1945 .\end{array}$ \\
\hline Séptima cúspide & $\begin{array}{l}2 \mathrm{~g} \text { rados de expresión: presencia y } \\
\text { ausencia. }\end{array}$ & $\begin{array}{l}\text { Selenka, } 1898 . \\
\text { Dahl berg, } 1945 .\end{array}$ \\
\hline $\begin{array}{l}\text { Protostílido o tubérculo de } \\
\text { Bolk. }\end{array}$ & $\begin{array}{l}4 \text { grados de expresión sobre el primer } \\
\text { molar inferior: ausencia, fosa, canal, } \\
\text { cúspide adherida cúspide libre. }\end{array}$ & $\begin{array}{l}\text { Dahlberg, } 1956 \text { (con modificaciones) y } 1963 . \\
\text { Brabant, } 1972 .\end{array}$ \\
\hline
\end{tabular}

Tabla II. Procedencia de la colección, número de cráneos y procedencia geográfica de los cráneos araucanos, adulto/maduro utilizados por Bollini et al., 2004.

\begin{tabular}{lcl}
\hline \multicolumn{1}{c}{ Colección } & $\begin{array}{c}\mathrm{N}^{\circ} \text { de } \\
\text { cráneos }\end{array}$ & Procedencia geográfica \\
\hline Pampa Grande & 6 & Provincia de Sal ta \\
Antofagasta & 4 & Provincia de Catamarca \\
Cal chaquíes & 7 & Provincia de Salta \\
Tastil & 19 & Provincia de Sal ta \\
Aymara & 43 & Provincia de Jujuy \\
\hline
\end{tabular}

\section{RESULTADOS}

Se analizaron la estructura dentaria de la serie craneana de araucanos, teniendo en cuenta los valores absolutos y relativos para cada variable estudiada, el estado de la muestra por pieza dentaria y la consecuente caracterización de la muestra según los valores de distribución de las frecuencias de las variables.

Se han relevado las frecuencias absolutas y relativas de las variables dentales, con el fin de caracterizar el patrón 
morfológico dental de la serie estudiada. Los resultados del análisis morfológico son presentados en la Tabla III. La Tabla IV muestra las variables y poblaciones consideradas para el análisis comparativo, y la Tabla $\mathrm{V}$ y Fig. 3 ilustran el distanciamiento biológico calculado entre las poblaciones consideradas a partir del análisis dental.

Tabla III. Frecuencias absolutas y relativas de las variables dentales analizadas en una serie prehistórica de araucanos provenientes de la Patagonia argentina.

\begin{tabular}{|c|c|c|c|c|}
\hline Rasgo & Tipo dental & Grado de expresión & $\mathrm{n}$ & $\%$ \\
\hline \multirow[t]{5}{*}{ Forma en pala } & Incisivos centrales superiores & Ausente & 1 & 14.29 \\
\hline & & Moderado & 6 & 85.71 \\
\hline & Incisivos laterales superiores & Ausente & 1 & 14.29 \\
\hline & & Moderado & 5 & 71.42 \\
\hline & & Marcado & 1 & 14.29 \\
\hline \multirow[t]{5}{*}{ Forma en doble pala } & Incisivos centrales superiores & Ausente & 6 & 85.71 \\
\hline & & Tipos II & 1 & 14.29 \\
\hline & Incisivos laterales superiores & Ausente & 6 & 75.00 \\
\hline & & Tipo II & 1 & 12.50 \\
\hline & & Tipo III & 1 & 12.50 \\
\hline \multirow[t]{3}{*}{ Tubérculo lingual } & Incisivos centrales superiores & Ausente & 8 & 100.00 \\
\hline & Incisivos laterales superiores & Ausente & 5 & 83.33 \\
\hline & & Leve & 1 & 16.67 \\
\hline \multirow{2}{*}{ Surco de interrupción } & Incisivos centrales superiores & Ausente & 8 & 100.00 \\
\hline & Incisivos laterales superiores & Ausente & 6 & 100.00 \\
\hline \multirow{3}{*}{ Hendidura lateral } & Incisivos centrales superiores & Ausente & 8 & 100.00 \\
\hline & Incisivos laterales superiores & Presente & 2 & 28.57 \\
\hline & & Ausente & 5 & 71.43 \\
\hline \multirow[t]{4}{*}{ Forma en pala } & Caninos superiores & Ausente & 1 & 6.67 \\
\hline & & Leve & 12 & 80.00 \\
\hline & & Moderado & 1 & 6.67 \\
\hline & & Marcado & 1 & 6.67 \\
\hline \multirow[t]{2}{*}{ Forma en doble pala } & Caninos superiores & Presente & 6 & 35.29 \\
\hline & & Ausente & 11 & 64.71 \\
\hline \multirow{4}{*}{ Tubérculo lingual } & Caninos superiores & Ausente & 9 & 56.25 \\
\hline & & Leve & 2 & 12.50 \\
\hline & & Moderado & 4 & 25.00 \\
\hline & & Marcado & 1 & 6.25 \\
\hline \multirow[t]{2}{*}{ Número de cúspides } & Primeros premolares superiores & Bicuspídeo & 15 & 100.00 \\
\hline & Segundos premolares superiores & Bicuspídeo & 13 & 100.00 \\
\hline \multirow[t]{6}{*}{ Hipocono } & Primeros molares superiores & Ausente & 1 & 7.69 \\
\hline & & Tipos I y II & 3 & 23.08 \\
\hline & & Tipo III & 9 & 69.23 \\
\hline & Segundos molares superiores & Ausente & 4 & 36.36 \\
\hline & & Tipo I y II & 5 & 45.45 \\
\hline & & Tipo III & 2 & 18.18 \\
\hline \multirow[t]{4}{*}{ Carabelli } & Primeros molares superiores & Ausente & 9 & 81.82 \\
\hline & & Tipo I & 2 & 18.18 \\
\hline & & Tipo II & 1 & 9.10 \\
\hline & Segundos molares superiores & Ausente & 10 & 100.00 \\
\hline \multirow[t]{3}{*}{ Paracónulo } & Primeros molares superiores & Ausente & 4 & 100.00 \\
\hline & Segundos molares superiores & Presente & 1 & 12.5 \\
\hline & & Ausente & 7 & 87.5 \\
\hline \multirow{3}{*}{ Metacónulo } & Primeros molares superiores & Ausente & 7 & 100.00 \\
\hline & Segundos molares superiores & Presente & 1 & 12.5 \\
\hline & & Ausente & 7 & 87.5 \\
\hline \multirow[t]{3}{*}{ Entoconúlido } & Primeros molares inferiores & Presente & 3 & 33.33 \\
\hline & & Ausente & 6 & 66.67 \\
\hline & Segundos molares inferiores & Ausente & 7 & 100.00 \\
\hline \multirow[t]{3}{*}{ Metaconúlido } & Primeros molares inferiores & Presente & 1 & 11.11 \\
\hline & & Ausente & 8 & 88.89 \\
\hline & Segundos molares inferiores & Ausente & 7 & 100.00 \\
\hline \multirow[t]{2}{*}{ Protostílido } & Primeros molares inferiores & Ausente & 11 & 100.00 \\
\hline & Segundos molares inferiores & Ausente & 10 & 100.00 \\
\hline
\end{tabular}


Morfología dental de una serie prehistórica de araucanos provenientes de la Patagonia argentina y su relación biológica con otras poblaciones prehistóricas argentinas y del mundo. Int. J. Morphol., 24(4):705-712, 2006.

\begin{tabular}{|c|c|c|c|c|}
\hline Rasgo & Tipo dental & Grado de expresión & $\mathrm{n}$ & $\%$ \\
\hline \multirow[t]{3}{*}{ Forma en pala } & Incisivos centrales inferiores & Leve & 5 & 100.00 \\
\hline & Incisivos laterales inferiores & Ausente & 1 & 16.67 \\
\hline & & Leve & 5 & 83.33 \\
\hline \multirow[t]{2}{*}{ Forma en doble pala } & Incisivos centrales inferiores & Ausente & 5 & 100.00 \\
\hline & Incisivos laterales inferiores & Ausente & 6 & 100.00 \\
\hline \multirow[t]{4}{*}{ Tubérculo lingual } & Incisivos centrales inferiores & Ausente & 4 & 80.00 \\
\hline & & Leve & 1 & 20.00 \\
\hline & Incisivos laterales inferiores & Ausente & 5 & 83.33 \\
\hline & & Leve & 1 & 16.67 \\
\hline \multirow[t]{2}{*}{ Hendidura lateral } & Incisivos centrales inferiores & Ausente & 5 & 100.00 \\
\hline & Incisivos laterales inferiores & Ausente & 6 & 100.00 \\
\hline \multirow{2}{*}{ Surco de interrupción } & Incisivos centrales inferiores & Ausente & 5 & 100.00 \\
\hline & Incisivos laterales inferiores & Ausente & 6 & 100.00 \\
\hline \multirow[t]{2}{*}{ Forma en pala } & Caninos inferiores & Leve & 6 & 85.71 \\
\hline & & Marcado & 1 & 14.29 \\
\hline Forma en doble pala & Caninos inferiores & Ausente & 7 & 100.00 \\
\hline \multirow[t]{2}{*}{ Tubérculo lingual } & Caninos inferiores & Ausente & 6 & 85.71 \\
\hline & & Leve & 1 & 14.29 \\
\hline \multirow[t]{3}{*}{ Número de cúspides } & Primeros premolares inferiores & Monocuspídeo & 11 & 100.00 \\
\hline & Segundos premolares superiores & Monocuspídeo & 9 & 90.00 \\
\hline & & Bicuspídeo & 1 & 10.00 \\
\hline
\end{tabular}

Tabla IV. Frecuencias relativas de los rasgos analizados y el número total de cada grupo de las poblaciones comparadas para establecer distancias biológicas con la serie Araucanos. *Irish, 1997.

\begin{tabular}{|c|c|c|c|c|c|c|c|c|}
\hline \multirow[b]{2}{*}{ Variable } & \multicolumn{2}{|c|}{ Noroeste } & \multicolumn{2}{|c|}{ Sinodontos * } & \multicolumn{2}{|c|}{ Europa $*$} & \multicolumn{2}{|c|}{ Africa* } \\
\hline & $\%$ & $\mathrm{n}$ & $\%$ & $\mathrm{n}$ & $\%$ & $\mathrm{n}$ & $\%$ & $\mathrm{n}$ \\
\hline Forma en pala & 0.00 & 13 & 98.8 & 1922 & 17.0 & 141 & 28.1 & 413 \\
\hline Hipocono & 86.67 & 45 & 90.2 & 3639 & 79.4 & 228 & 99.0 & 772 \\
\hline Carabelli & 17.65 & 34 & 32.1 & 3194 & 47.4 & 230 & 51.2 & 683 \\
\hline Sexta cúspide & 9.09 & 11 & 47.8 & 2947 & 7.9 & 178 & 16.6 & 561 \\
\hline Séptima cúspide & 0.00 & 9 & 9.8 & 3998 & 5.8 & 223 & 38.5 & 568 \\
\hline Protostílido & 21.43 & 14 & 34.7 & 3739 & 20.0 & 200 & 21.0 & 556 \\
\hline
\end{tabular}

Tabla V. Distancias biológicas entre la serie araucanos y otras poblaciones.

\begin{tabular}{lcccl}
\hline MMD/Variable & Noroeste & Sinodonto & Europa & África \\
\hline Forma en pala & 0,43328248 & $\mathbf{0 , 1 1 2 8 3 6 8 2}$ & 2,14921407 & 1,41435585 \\
Hipocono & $-0,08163408$ & 0,34137173 & 0,02880739 & 1,10498006 \\
Carabelli & 0,04652842 & 0,01355763 & 0,31153024 & 0,41717212 \\
Sexta cúspide & $-0,19187211$ & $-0,02389753$ & 0,32028741 & 0,040465 \\
Séptima cúspide & 0,25988824 & $-0,10952649$ & $-0,078272$ & 0,32151501 \\
Protostílido & $-0,13536999$ & 1,49593887 & $\mathbf{0 , 7 6 3 9 6 7 3 3}$ & 0,81372513 \\
\hline Total & 0,12328319 & $\mathbf{0 , 3 2 7 2 8 4 5 7}$ & $\mathbf{0 , 5 8 2 5 8 9 0 7}$ & 0,68536886 \\
\hline
\end{tabular}

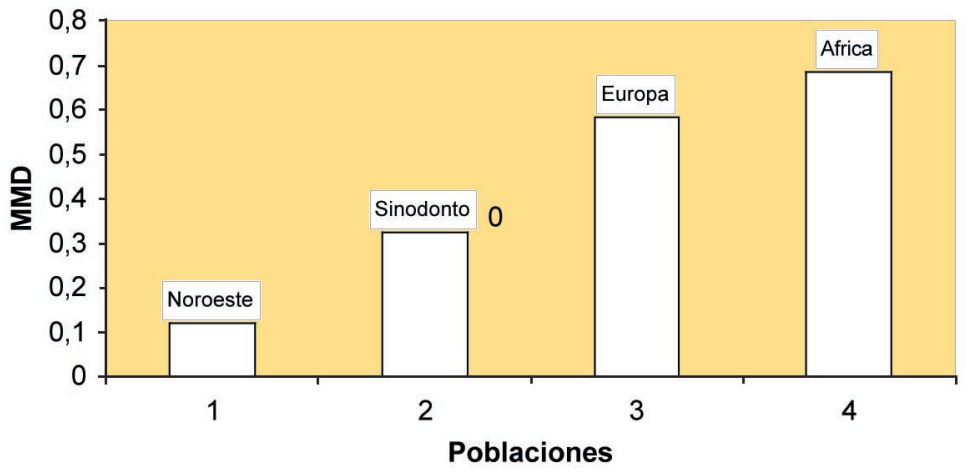

Fig. 3. Distancias biológicas entre la muestra estudiada en araucanos y las distintas poblaciones mundiales. 


\section{DISCUSIÓN}

Lo que se desprende de la interpretación de los valores encontrados, tanto a nivel descriptivo como comparativo, es la clara evidencia de un patrón morfológico dental donde se destaca la aparición de formas dentales bien definidas.

Incisivos. Se observan altos porcentajes de forma en pala en los incisivos superiores anteriores y laterales $(85,71 \%)$. $\mathrm{Su}$ ausencia es de 14,29\% en los incisivos centrales y laterales, siendo el rasgo pala de tipo "moderada", la única hallada en los incisivos anteriores y la que predomina $(71,42 \%)$ en los laterales. No se ha hallado pala leve.

Krogman \& Iscan (1986) aportan una serie de porcentajes para definir patrones característicos de cada grupo original o poblaciones originales. Observan valores superiores al $80 \%$ de la keilomorfía en poblaciones chinas y frecuencias muy bajas en caucasoides y negroides. Esto fue descrito también por Hrdlicka (1920, 1921) en poblaciones asiáticas, mostrando porcentajes muy similares a los hallados en la muestra argentina estudiada (poblaciones chinas: 82,7\% para el incisivo anterior, 77,9\%; en japoneses para el incisivo central; $72,7 \%$ para el incisivo lateral; y $75 \%$ y $62,5 \%$, respectivamente para los incisivos centrales y laterales en mongoles). Hrdlicka también presenta frecuencias de $68.8 \%$ en los incisivos laterales (Brabant). Moorrees (1957) encuentra, para el mismo tipo de pala, 65\% para el incisivo lateral en aleutianos y Dahlberg (1947 y 1951) el 89,5\% para la misma pieza dental en los indios Pima. Los valores encontrados para "pala moderada" son mayores a los valores que se corresponden con los de las poblaciones mongoloides encontrados por otros autores (Brabant) en poblaciones chinas $(23,4 \%$ y $24 \%$ en los incisivos centrales y laterales, respectivamente); $18 \%$ (incisivos anteriores) y 20,3\% (incisivos laterales) en poblaciones japonesas, y $29 \%$ y $25 \%$ en las poblaciones mongolas, en incisivos centrales y laterales, respectivamente. Devoto et al., hallan en una población del Noroeste argentino, 100\% de pala, siendo la mayor frecuencia la pala marcada (49\%), seguida por pala moderada $(35 \%)$ y pala leve $(16 \%)$.

La doble pala en los incisivos superiores está representada en un $14,29 \%$ sólo por el tipo 2, mientras que en los laterales no se observa en un $75 \%(85,71 \%$ en los incisivos anteriores) con representación de los tipos 2 y 3 . Estos valores se aproximan a los expresado por Matsumura (1995), quien encontró valores para la doble pala de $14,8 \%$ en los iroqueses de Ontario, 13,4\% en las poblaciones de Illinois, 11,4\% en los mexicanos, $16,1 \%$ en las poblaciones peruana y $25,4 \%$ en las poblaciones de California. Las poblaciones asiáticas con los valores de doble pala más elevados son las chinas del Noreste $(10,7 \%)$ y las japonesas de Kofún con 9,7\%.
El tubérculo dental está poco desarrollado en los incisivos laterales $(16,67 \%)$ sólo expresándose en forma leve; mientras que se halla totalmente ausente en los anteriores. Los valores observados en otras poblaciones mundiales que se acercan a lo hallado en la muestra estudiada se encuentra en grupos indonesios, chinos del noreste, japoneses modernos, iroqueses y peruanos con ausencia de tubérculo dental en el incisivo anterior. Frecuencias de alrededor del 16,67\% en los incisivos laterales hallamos en poblaciones yayoi (14\%), isleños de Southampton (16,7\%), aborígenes australianos (16,6\%), $13 \%$ poblaciones de la columbia británica; frecuencias mayores se hallan en las poblaciones jomonesas (22,2\%), según Matsumura.

No se ha hallado surco en el tubérculo lingual en ninguno de los incisivos y sólo aparece hendidura lateral en los incisivos 2 (28,57\%), ya que los anteriores no presentan este rasgo. Muy leve es la aparición de pala y doble pala en los caninos, presentándose el tubérculo lingual variable en estructura y presencia en estas piezas dentarias. Todos los premolares estudiados superiores son bicúspides. El gran desgaste de sus coronas no permitió analizar la presencia del tubérculo de De Terra.

Respecto a la estructura del hipocono en los molares analizados, observamos una predominancia del tipo 3 en los primeros molares y una importante reducción y desaparición en los segundos molares, ya que el $36,36 \%$ no presentó cúspide y el 45,45\% mostró un hipocono reducido o muy reducido respecto a la estructura del metacono. Si comparamos nuestras observaciones con las realizadas por otros autores, veremos que esta cúspide presenta valores de aparición de 95,1\% en grupos de la polinesia, 90,8\% en Oahu y 85,3\% en Hawai según valores aportados por Hanihara (1990).

Turner (1984) halla valores de $94,7 \%$ para poblaciones asiáticas del Noreste de Asia, 79,8\% para esquimales, $81,7 \%$ para poblaciones del Noroeste europeo y valores de $91,7 \%$ y $92,6 \%$ para poblaciones de aborígenes norteamericanos y sudamericanos, respectivamente. Hanihara (1990) presenta valores más elevados para la reducción del hipocono dando valores similares a los hallados en la muestra estudiada en las poblaciones americanas de California (35,6\%), México $(30,3 \%)$, isleños de Southampton $(35,4 \%)$, Ilinois $(29,7 \%)$ y la Columbia Británica $(27,9 \%)$.

Respecto a la aparición del tubérculo de Carabelli en el primer molar superior, se observan valores similares en algunas de las poblaciones descriptas por Matsumura, principalmente en las de origen asiático, ellas son: los Ainu (19,2\%), 
las poblaciones chinas del Noreste (19,2\%), Yayoi (19,2\%), japoneses de Kofún (19,2\%), las poblaciones neolíticas de Thai $(19,2 \%)$ y las poblaciones mongolas $(19,2 \%)$. Entre las poblaciones americanas, cuyas frecuencias son en general menores para este mismo autor, hallamos valores de 19,2\% en Illinois, $16,5 \%$ en mexicanos y $14,2 \%$ en poblaciones peruanas. Para Hanihara (1990) las frecuencias de aparición del tubérculo de Carabelli son de 13,3\% para las poblaciones polinesias del Este (que incluye islas Marquesas, Gambier, Society y Tuamotu), $13,2 \%$ para las islas Hawai y $18,4 \%$ para Oahu. Los valores hallados por Turner (1984) son en general más elevados, donde se observa la mayor similitud a las frecuencias de la muestra araucana analizada, es en las poblaciones esquimales $(17,5 \%)$ y de la gran costa noroeste $(24,8 \%)$.

Las cúspides menores de los molares superiores, como el paracónulo y el metacónulo se presentan sólo en el segundo molar, con frecuencias del 12,5\% para ambas cúspides. Las cúspides menores de los molares inferiores se analizaron en primeros y segundos molares pero, como era de esperar fueron halladas sólo en los primeros molares. La sexta cúspide mostró una frecuencia de aparición de 33,33\%, similar a los valores hallados en las poblaciones Yayoi (28,6\%), Indonesia $(31,8 \%)$, poblaciones de California (37\%), México (27,4\%) y Ontario $(37,7 \%)$ descritas por Matsumura; mientras que la séptima cúspide se presenta en un $11,11 \%$; valores similares a los hallados en las poblaciones Ainu (12\%), isleños de New Britain (11,5\%), Illinois $(10,2 \%)$, peruanas $(12,8 \%)$ y Yayoi $(12,3 \%)$ descritas por este mismo autor. Similares valores han sido hallados en las poblaciones descritas por Turner (1984) del Noreste de Asia (10\%), esquimales (12,9\%) y poblaciones de aborígenes norteamericanos $(10,2 \%)$.

Respecto al protostílido, no ha sido hallado en la muestra estudiada y representa una variación importante respecto a lo esperado ya que la aparición del éste se haya descrita en la mayoría de las poblaciones estudiadas por otros autores. Matsumura halla valores del $0.0 \%$ en aborígenes australianos y frecuencias muy bajas en japoneses de Kamakura (3,9\%), poblaciones aleutianas $(1,4 \%)$, y poblaciones de Amami y Okinawa $(2,3 \%)$. Otras características propias de esta serie craneana se halla en una leve formación en pala de los incisivos inferiores, más marcado este rasgo en los incisivos anteriores $(100 \%)$ que los inferiores $(83,33 \%)$. No se ha observado ni doble pala, ni surco en el tubérculo dental ni hendiduras laterales en estos mismos dientes, mientras que el tubérculo dental está ausente (80\% en incisivos centrales y 83,33\% en incisivos laterales) o se halla representado muy levemente (20\% y $16.67 \%$ en incisivos anteriores y laterales respectivamente).

En conclusión, si observamos los valores obtenidos en las distancias calculadas, es posible considerar la inclusión de las muestras araucanas analizadas en un perfil mongoloide sinodonte generalizado, alejándose progresivamente de las poblaciones caucasoides europeas y africanas. La mayor afinidad biológica es encontrada en conjunto con las poblaciones del noroeste argentino, comportamiento morfológico que puede ser explicado por la cercanía geográfica que presentan las muestras comparadas entre sí.

BOLLINI, G. A.; RODRÍGUEZ-FLÓREZ, C. D.; COLANTONIO, S. E. \& MÉNDEZ, M. G. Dental morphology in a prehistoric sample of Araucanos from Patagonia and his biological relationship with other prehistoric populations from Argentina and the world. Int. J. Morphol., 24(4):705-712, 2006.

SUMMARY: Presence of 25 dental traits in a sample of pre-conquest mature skulls kept in Museo de La Plata (Argentina) has been analyzed. Both arches upper and lower and all permanent dental pieces has been registred, except third molars. This study establish dental morphology patterns from a statistical point of view. We conluded that statistical frequences show high similarity with populations associated to mongoloid dental complex and move away of European and African populations. complex.

KEY WORDS: Dental morphology; Dental traits; Prehistoric Araucanos; Mean Measure of Divergence; Mongoloid

\section{REFERENCIAS BIBLIOGRÁFICAS}

Bollini, G. A.; Méndez, M. G.; Rodíguez-Flores, C. D. \& Collantonio, S. E. Antropología dental de una serie prehistórica de araucanos provenientes de la Patagonia Argentina. Revista de Arqueología Americana, 23: 2004.

Brabant, H. Bulletins et Memoires de la Societé D'Antropologie de París. Tomo $9^{\circ}$ - XII Serie $N^{\circ} 4,1972$.
Dahlberg, A. A. The paramolar tubercle (Bolk). Am. J. Phys. Anthrop., 3:97-103, 1945.

Dahlberg, A. A. \& Mikkelsen, O. The shovel- shaped character in the teeth of the Pima Indians. Am. J. Phys. Anthrop., $5: 234-5,1947$. 
Dahlberg, A. A. The dentition of the American Indians. In W. S Laughlin (ed.). The Physical anthropology of the American Indians. New York, Viking Fund, 1951. pp. 138-76.

Dahlberg, A. A. Materials for the establishment of standards for classifications of tooth characters attributes and techniques in morphological studies of the dentition. Zooler Laboratory Dental Anthropology. University of Chicago (mimeo.) 1956.

Dahlberg, A. A. Analysis of the American Indian Dentition. In Brothwell D. (Ed.) Dental Anthropology. Londres, Pergamon Press., 1963. pp. 149-77.

Devoto, F. C. H; Arias, N. H.; Ringuelet, S. \& Palma, N. H. ShovelShaped Incisors in a Northwestern Argentine Population. J. Den. Res., 47(5):820-3, 1968.

Devoto, F. C. H. Morfología dental de la población precolombina de Tastil. In: Tastil una ciudad preincaica argentina. Proyecto y dirección. E. M. Cigliano. Ed. Cabargon. Buenos Aires, 1973.

Goaz, P. W \& Miller, M.C. A preliminary description of the dental morphology of the Peruvian Indians. J. Dent. Res., 45:106-19, 1966.

Hanihara, K. Mongoloid dental complex in the decidouous dentition. Zinrulgaku Zassi., 7:9-20, 1966.

Hanihara, K. Statistical and comparative studies of the Australian Aboriginal dentition. Univ. Mus., Univ. Tokyo, Bull., 11:1-57, 1976.

Hanihara, T. Dental anthropological evidence of affinities among the Oceania and the Pan-Pacific populations: The basic populations in East Asia, II. J. Anthrop. Soc. Nippon, 98:23346, 1990.

Harris, E. F. \& Bailit, H. L. The metaconule: A Morphologic and Familial Analysis of the Molar Cusp in Humans. Am. J. Phys. Anthrop., 53:349-58, 1980.

Hrdlicka, A Shovel-shaped teeth. Am. J. Phys. Anthrop., 3: 429-65, 1920.

Hrdlicka, A. Further studies of tooth morphology. Am. J Phys. Anthrop., 4:141-76, 1921.

Irish, J. D. Characteristic high and low frequency dental traits in sub-saharran African populations. Am. J. Phys. Anthrop., 102:133-67, 1997.

Korenhof, C. A. W. Morphogenetical Aspects of the Human Upper Molar. Utrecht, Acad. Proefschrift, Uitgeversmaatschappij Neerlandia, 1960.

Kraus, E. B. S. Carabelli's anomaly of the maxillary molar teeth: Observations on Mexicans and Papago Indians and an interpretation of the inheritance. Am. J. Hum. Genet., 3: 348$55,1951$.
Krogman, W. M. \& Iscan, M. Y. The Human Skeleton. In Forensic Medicine. Springfield, lllinois. Charles C. Thomas Pub. 1986.

Marcellino, A. J. \& Colantonio, S. E. Los cráneos aborígenes más antiguos de Argentina: un ensayo clasificatorio. En Caro Dobón, L.; Rodríguez Otero, H.; Sánchez Compadre, E. (edit) Tendencias actuales de investigación en la Antropología Física española.). Editorial Universidad de León, España, 2000. pp. 20518 ,

Matsumura, H. Dental Characteristics Affinities of the Prehistoric to Modern Japanese with the East Asians, American natives and Australo-Melanesians - Anthropol. Sci. 103(3):235-61, 1995.

Moorrees, C. F. A. The aleut dentition. A correlative study of dental characteristics in an Eskimoid people. Harvard University Press, Cambridge, 1957.

Richards, L. C. \& Telfer, P. J. The use of dental characters in the assessment of genetic distance in Australia. Archaeology and Physical Anthropology in Oceania 14(3):184-94, 1979.

Rodríguez-Cuenca, J. V. Avances de la Antropología dental en Colombia. Universidad Nacional de Colombia. Santa Fé de Bogotá, 1999.

Scott, R.G. \& Turner II, C. G. The anthropology of modern human teeth. Cambridge University Press. 1997.

Snyder, N. G. Mesial margins ridgins of incisor labial Surfaces. J. Dent. Res., 39(2):361, 1960.

Townsend, G. C. \& Martin, N.G. Fitting genetic models to Carabelli trait data in South Australian twins. J. Dental Res. 71:403-9, 1992.

Turner, II, C. G. Advances in the Dental Search for Native American Origins. Acta Anthropogenetica, 8(1-2):23-78, 1984.

Turner II, C. G. Dientes y prehistoria en Asia y América. Investigación y Ciencia 151. Prensa Científica, Barcelona, 1989.

Turner, II C. G.; Nichol, C. R. \& Scott, G. R. Scoring Procedures for Key Morphological Traits of the Permanent Dentition: The Arizona State University Dental Anthropology System. In: Advances in Dental Anthropology,13-31, 1991.

Dirección para correspondencia:

Gabriel A. Bollini

Calle 42 № $33 a-67$

Tulua

$\operatorname{COLOMBIA~}$

Recibido : 25-03-2006

Aceptado: 24-09-2006 